\title{
Fiódor Dostoiévski pelo viés lotmaniano
}

\section{Ekaterina Vólkova Américo*}

RESUMO: O objetivo do artigo é abordar a presença de Fiódor Dostoiévski na obra do semioticista e teórico literário Iúri Lotman. A análise das duas coletâneas de seus textos, Sobre a literatura russa e Semiosfera revela as menções constantes de Dostoiévski tanto nos textos dedicados às questões literárias, quanto semióticas. Lotman divide os principais escritores russos do século XIX em os que seguem, em sua obra, o modelo binário (como Gógol, Liérmontov e Dostoiévski) ou ternário (como Púchkin, Tolstói, Tchékhov). No caso de Dostoiévski, as características binárias podem ser percebidas tanto no nível de enredo, quanto no que diz respeito aos personagens. Ambos os modelos, tanto o binário quanto o ternário, são partes inseparáveis da cultura russa, responsáveis, inclusive, pela sua dinamicidade. Dostoiévski ainda é apontado como um escritor profundamente simbólico, o que torna a sua obra um terreno extremamente fecundo para os estudos semióticos. O par Dostoiévski-Tolstói marcou o período mais importante da cultura russa, em que ela deixou de ser receptora de textos estrangeiros e passou a emitir os seus próprios textos para o exterior.

PALAVRAS-CHAVE: Iúri Lotman; Feodor Dostoiévski; semiótica da cultura; literatura russa.

ABSTRACT: The aim of this article is to describe the presence of Fyodor Dostoevsky in the oeuvre of literary theorist and semiotician Yuri Lotman. The analysis of two collections of his writings, On the Russian literature and Semiosphere reveals the Dostoevsky's entries both in texts dedicated to literary and semiotic issues. Lotman divides the main Russian writers of the nineteenth century in those who followed in their writings the binary model (as Gogol, Lermontov and Dostoevsky) or ternary model (as Pushkin, Tolstoy, and Chekhov). In Dostoevsky's case the binary features can be realized both in the plot level, and in regard to the characters. Both models, the binary and the ternary, are inseparable parts of Russian culture, responsible for its dynamism. Dostoevsky is also appointed as a deeply symbolic writer which makes his work an extremely fertile ground for semiotic studies. The Dostoevsky-Tolstoy couple marked the most important period of the Russian culture in which it was no longer receiving foreign texts and started to emit its own texts abroad.

PALAVRAS-CHAVE: Yuri Lotman; Fyodor Dostoevsky; Semiotics of Culture; Russian Literature.

\footnotetext{
* Doutora em Literatura e Cultura russa pelo Programa de Pós-graduação em Literatura e Cultura Russa da USP. Professora de Literatura e Língua Russa da Universidade Federal Fluminense.
} 


\section{Introdução}

A literatura russa foi o tema central dos estudos do semioticista russo Iúri Lótman. Em sua volumosa obra, foram abordadas diferentes épocas e escritores, tanto os eminentes como Púchkin, Gógol, Liérmontov, Tolstói, Dostoiévski e Tchékhov, quanto os menos famosos e até mesmo desconhecidos, como é o caso do filólogo e poeta Andrei Kaissárov. Nos primeiros trabalhos, escritos ainda na época em que estudava na Universidade de Leningrado, Lotman se interessava mais pelo limiar dos séculos XVIII- XIX e, mais precisamente, pelo fenômeno do Iluminismo Russo e pela vida e obra de seus representantes mais notáveis, como Aleksandr Radíschev e Nikolai Karamzin. Em parte, esse interesse se explica pela influência dos seus mestres na Universidade, principalmente Grigori Gukóvski e Nikolai Mordóvtchenko. Já os seus escritos posteriores abarcam a obra dos escritores clássicos da literatura russa do século XIX e até mesmo do século XX, como, por exemplo, Marina Tsvetáieva, Vladímir Maiakóvski, Boris Pasternak, Mikhail Bulgákov. Provavelmente, essa ampliação do campo de estudos ocorreu devido à sua atuação como professor de literatura russa na Universidade de Tártu, atividade à qual ele se dedicou com grande paixão desde a década dos 1950 até os últimos anos da sua vida. De modo geral, a trajetória científica de Lótman pode ser traçada como um movimento que partiu de autores e fenômenos isolados para depois abranger os processos gerais da cultura russa e universal.

Embora a obra de Lotman costume ser abordada ora do ponto de vista semiótico, ora como crítica da literatura russa, ambas as áreas, a semiótica e a literatura, coexistem nela de forma bastante harmoniosa. Assim, a literatura russa manifesta-se como uma fonte riquíssima para exemplificar as questões semióticas e, por sua vez, é analisada como uma estrutura semiótica complexa. Vejamos a seguir qual é o lugar atribuído a Dostoiévski na abordagem lotmaniana que pode ser definida como estrutural-semiótica (NEKLIÚDOV, 2006).

\section{Um Dostoiévski semiótico}

Devido ao extenso volume da obra lotmaniana (afinal, são mais de oitocentos textos), no âmbito do presente artigo não será possível avaliar todo o seu conjunto para definir o grau de presença de Dostoiévski neles. Com o objetivo de confirmar se Dostoiévski é citado tanto nos textos de cunho semiótico quanto nos de crítica literária, limitamos a nossa pesquisa às coletâneas Sobre a literatura russa (LOTMAN, 1997) e 
Semiosfera (LOTMAN, 2001). Tomamos a liberdade de incluir o artigo "A literatura russa da época pós-petrina e a tradição cristã" (LOTMAN, 1994), que consideramos um dos mais significativos para a compreensão da concepção lotmaniana da história da literatura russa. A escolha das coletâneas Sobre a literatura russa (1997) e Semiosfera (2001) como a principal fonte do nosso estudo é amparada pelo fato de as mesmas reunirem os mais notáveis trabalhos de Lotman, o que, por sua vez, sustenta as observações apresentadas a seguir.

O primeiro fato importante a ser constatado a partir da análise do índice de autores citados é que há muitas referências a Dostoiévski tanto no que diz respeito aos estudos semióticos quanto aos literários, embora a primazia, entre todos os clássicos russos, seja de Aleksandr Púchkin.

Os sumários das coletâneas revelam outro traço interessante: a julgar pelos títulos, nelas estão ausentes artigos dedicados exclusivamente a Dostoiévski ou a seus escritos. Um dos motivos para isso pode ser o critério usado pelos editores russos, que selecionaram os textos de caráter panorâmico, que objetivam descrever os processos gerais literários e semióticos e não os fenômenos e escritores concretos. No entanto, o mesmo não ocorre em relação a outros autores clássicos. Assim, em Sobre a literatura russa encontramos textos dedicados à obra de Mikhail Liérmontov: "'O Fatalista' e o problema do Leste e do Oeste na obra de Liérmontov" (LOTMAN, 1997, p. 605-620); vários sobre Gógol e sua obra: “O espaço artístico na prosa de Gógol” (Op. cit., p. 621658), "Sobre Khlestakov" (Op. cit., p. 659-688), "Sobre o realismo de Gógol” (Op. cit., p. 694-711) e também sobre Tolstói: “As fontes da 'corrente tolstoiana' na literatura russa dos anos 1830" (Op. cit., p. 548-593). Vale lembrar ainda que, embora o nome de Aleksandr Púchkin também esteja ausente dos títulos dos artigos dessa coletânea, existe um volume inteiro dedicado à sua obra (LOTMAN, 2003). A única vez em que o nome de Dostoiévski aparece no título é no caso do artigo "Dois contos improvisados de Búnin (Sobre a questão 'Búnin e Dostoiévski')” (Op. cit., 730- 742) ${ }^{1}$. Porém, vale atentar para o fato de que aqui Dostoiévski é mencionado em conjunto com um outro escritor, Ivan Búnin. Vejamos como ocorre o confronto entre os dois autores.

O artigo se inicia com uma afirmação provocativa (traço que em geral caracteriza os textos lotmanianos) de que "Búnin não gostava de Dostoiévski. Esse fato é bem conhecido e sustentado por vários testemunhos" (Op. cit., p. 730). Porém, em

\footnotetext{
${ }^{1}$ Meus agradecimentos a Elena Vássina que atentou para a existência desse artigo.
} 
seguida, Lotman a questiona e observa que trata-se de uma competição com a tradição literária por parte de Búnin, de um desejo de continuá-la e superá-la. Portanto, Dostoiévski seria um dos principais precursores de Búnin e "há todos os motivos para afirmar que Dostoiévski era um interlocutor constante e pungente de Búnin e que a polêmica com ele esteja por trás de muitas obras do autor das 'Aleias escuras"” (Op. cit., p. 742).

Lotman destaca ainda as duas tradições que Búnin distinguia na literatura russa. A primeira delas seria a "petersburguesa", europeia, não-russa, representada por Gógol e Dostoiévski, sendo que o primeiro era de origem ucraniana e o segundo tinha ascendência polonesa. Para Búnin, a obra de Dostoiévski seria afastada da natureza e, por conseguinte, estranha. "Essa tradição, Búnin considerava como inimiga”, conclui Lotman (Op. cit., p. 741). A segunda tendência, percebida por Búnin como genuinamente russa e ligada à natureza, é relacionada ao nome de Tolstói. Curiosamente, essa divisão em escritores "petersburgueses" e "naturais" ressurge na concepção do próprio Lotman da literatura russa. Por exemplo, em "A simbologia de Petersburgo" (LOTMAN, 2001, p. 320-335)², a obra de Gógol e de Dostoiévski é vinculada à mitologia da cidade de São Petersburgo, parte fundamental da cultura russa.

De modo geral, nos artigos lotmanianos de cunho panorâmico, Dostoiévski é constantemente lembrado ao lado de Tolstói, sendo que ambos representam para Lotman duas tendências opostas, porém essencialmente interligadas, que marcaram os caminhos da literatura russa ao longo do século XIX e encontraram sua continuação no século posterior. Trata-se de uma abordagem por meio das oposições binárias, um dos típicos procedimentos da semiótica da cultura. Lotman começa o artigo "Sobre a literatura russa do período clássico" (LOTMAN, 1997 [1992], p. 594-604), um dos últimos escritos (ou, mais precisamente, ditados) por ele, com uma afirmação de que "a literatura russa entre Púchkin e Tchékov representa uma união" (Op. cit., p. 594), embora possa ser dividida em romantismo e realismo, em período de predominância da poesia ou da prosa. O período anterior a este seria o de Lomonóssov a Karamzin, e o período posterior começa com Blok e os simbolistas e continua até o presente momento. A história da literatura é vista por Lotman como um processo dinâmico, em que se alternam as épocas de um desenvolvimento relativamente tranquilo e os momentos explosivos "que se caracterizam por mudanças bruscas de todo o mapa do universo

\footnotetext{
${ }^{2} \mathrm{O}$ artigo foi minuciosamente analisado e traduzido para o português por Edelcio Américo em sua dissertação de mestrado: Texto de São Petersburgo na literatura russa (FFLCH, USP, 2006).
} 
cultural" (Idem). No entanto, apesar dessa unidade, a dinâmica da literatura russa também pode ser vista como uma coexistência de dois modelos: o binário e o ternário. A visão binária pressupõe a divisão do mundo em oposições como, por exemplo, o positivo e o negativo, o sagrado e o diabólico, o natural e o artificial. Entre os escritores clássicos russos que recriam o modelo binário em suas obras estão principalmente Liérmontov, Gógol e Dostoiévski. Em seus escritos, as oposições refletem inclusive no nível do enredo: não se trata apenas de um embate entre o bem e o mal, mas de um modelo mais complexo: "o caminho para o bem é possível apenas ao atingir o grau extremo do mal, passar por arrependimento, transfiguração, ressurreição e transformação em um ser mais elevado" (Op. cit., p. 597). A vida representa uma espécie de "prova e o protagonista mergulha nela como se fosse no inferno" (Idem). Esse tipo de enredo origina-se em narrativas medievais sobre o Grande Pecador, principalmente apócrifos, para depois ressurgir na obra dos românticos e, por fim, encontrar o seu auge em Gógol e Dostoiévski.

Entre as obras que mais evidenciam o enredo binário Lotman cita Almas mortas, de Gógol, e Os irmãos Karamázov, de Dostoiévski. Como se sabe, Gógol pretendia originalmente criar o seu "poema em prosa" Almas mortas composto por três volumes (sendo que só o primeiro chegou a ser finalizado), correspondentes à estrutura da Divina comédia: o primeiro equivaleria ao inferno, o segundo ao purgatório e o terceiro ao paraíso. Porém, se para Dante existiam todas essas três dimensões, para os escritores russos a história termina quando o protagonista chega ao limiar do paraíso. "Esse momento, para os escritores russos, encontra-se fora dos limites da arte" (Idem). O mesmo pode-se dizer em relação aos personagens de Dostoiévski, como Rodion Raskólnikov e os irmãos Karamázov. É assim o desfecho de Crime e castigo:

\footnotetext{
Mas aqui já começa outra história, a história da renovação gradual de um homem, a história do seu paulatino renascimento, da passagem progressiva de um mundo para o outro, do conhecimento de uma realidade nova, até então totalmente desconhecida. Isto poderia ser tema de um novo relato - mas este está concluído (DOSTOIÉVSKI, 2001, p. 561).
}

Inicialmente, os românticos ficaram encantados pela beleza do mal e da revolta contra o mundo, o que pode ser observado, por exemplo, em $O$ demônio, de Liérmontov, e na sua repercussão posterior na arte russa, inclusive no quadro $O$ demônio, de Mikhail Vrúbel. 


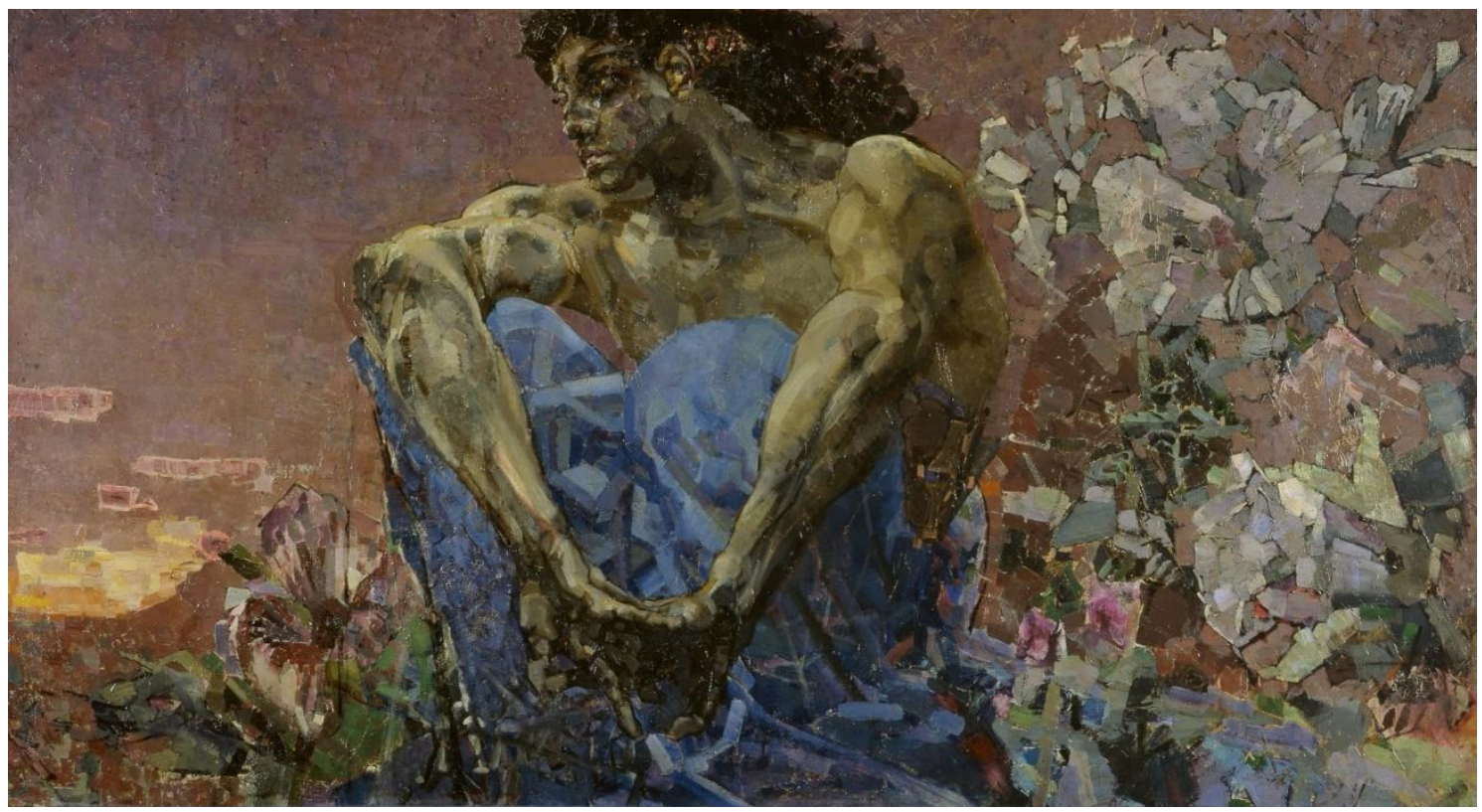

Mikhail Vrúbel. O demônio sentado (1890).

Nos escritos de Gógol e Dostoiévski o mal recebe uma justificativa a mais para se tornar objeto da arte: é um momento-chave em que se inicia a elevação ao bem. Porém, atenta Lotman, não se trata de um mal pequeno, pois "um pecado mesquinho e vulgar está mais longe do bem do que um pecado grande; um grande pecador encontrase no meio do caminho que pode levá-lo à santidade" (Idem). É justamente por isso que Dmítri Karamázov, apesar das suas paixões incontroláveis, é inocente aos olhos do leitor, apesar de não ser absolvido de fato no romance.

O modelo binário é oposto ao ternário que se desenvolveu na cultura russa de modo paralelo. Além dos planos do bem e do mal, a perspectiva ternária inclui o nível intermediário, que não é bom nem ruim, ou seja, é o nível da vida terrestre, cotidiana. Inicialmente, esse modelo foi explorado na literatura russa por Púchkin, depois repercutiu na obra de Tolstói e encontrou seu ápice em Tchékhov. A oposição entre o bem e o mal também está presente nesse modelo, porém de forma diferente:

Desse ponto de vista, o mal é concebido como desvio das possibilidades que a personalidade humana possui e o bem como realização delas. Tanto o bem quanto o mal estão fundidos simultaneamente na personalidade humana e realizam-se de forma pura em dois elementos opostos do esquema ternário (Op. cit., p. 598).

Na obra de Tolstói, em que o modelo ternário alcançou o seu vértice, todos os personagens estão situados no plano da vida cotidiana e, portanto, entre o bem e o mal. De acordo com Lotman, há personagens que procuram se livrar do mal e encontrar o 
bem: são os "personagens do caminho" (Op. cit., p. 598). São assim Andrei Bolkónski, Pierre Bezúkhov e Liévin. Há ainda os "personagens de existência" (Idem), como Platon Karatáiev, que se encontram no plano da vida cotidiana, justificado pelo próprio fato da sua existência e, portanto, livre do julgamento moral. O modelo ternário traz a ideia de que a vida é essencialmente moral por sua natureza e que o mal é um desvio do caminho natural. Obviamente, trata-se de uma interpretação peculiar que as ideias de Rousseau receberam na cultura russa em que a personalidade humana é concebida como genuinamente nobre, mas que é destorcida pela influencia da sociedade civilizada.

No esquema ternário, a realidade é o ponto de partida para alcançar o modelo. Já no esquema binário, o pensamento flui na direção contrária: do modelo à realidade. Assim, "em Dostoiévski, a ideia é ilustrada por meio da realidade, e em Tolstói a realidade entra em conflito com o sistema ideológico e sempre representa algo mais rico" (Op. cit., p. 599).

Por fim, Lotman adverte contra a tentação de justapor ambos os modelos, o binário e o ternário, e definir um como genuinamente russo e outro como resultado da influência das outras culturas, pois ambos representam a essência da cultura russa. $O$ modelo ternário surgiu como resultado do cruzamento de dois ou mais modelos binários: assim, na Rússia, a binaridade própria ao cristianismo se fundiu com a consciência popular pagã. Essa combinação de elementos opostos faz da literatura russa uma estrutura semiótica complexa:

Justamente a coexistência dos dois modelos, o binário e o ternário, como um todo único e, ao mesmo tempo, a colisão dessas duas tendências é que criou a diversidade cultural necessária que proporcionou a dinamicidade do sistema como um todo (Idem).

Em todos os trabalhos de Lotman, tanto de caráter crítico-literário quanto semiótico, o papel central é atribuído à individualidade do criador, escritor e poeta. Assim, em seu artigo "semiótico" "O símbolo no sistema da cultura" (LOTMAN, 2001), a obra de Dostoiévski é citada como uma combinação de duas orientações próprias da cultura: a simbolizante e a dessimbolizante, sendo que a orientação geral do século XIX era a dessimbolizante, ou seja, "uma pessoa ou um personagem literário era visto como representante de uma ideia, de uma classe, de um grupo" (Op. cit., p. 242). Essa orientação marcou a obra de Dostoiévski que acompanhava com muita atenção as crônicas criminais dos periódicos e interpretava essas notícias como sintomas de 
patologias da sociedade e também como símbolos. Assim, os seus personagens, como ocorre em Os demônios, simbolizam certos fenômenos e tipos sociais, mas não se esgotam com isso, sempre sobra "algo mais", um mistério.

Lotman demonstra a simbologia em Dostoiévski ao comparar a sua narrativa com a de Tolstói (novamente os dois clássicos russos são confrontados). Para Tolstói a presença de múltiplos sentidos na palavra a deixava perigosa e mentirosa: "A vida privada das palavras (e da simbologia social) é, em sua essência natural, a pura verdade" (Op. cit., p. 244). Não é por acaso que o mais importante nos romances tolstoianos não é dito e sim sentido, vivido (como as revelações de Bolkónski e as declarações amorosas entre Pierre e Natacha, Liévin e Kitty). Já a palavra de Dostoiévski possui outro significado: "as palavras não nomeiam os objetos e as ideias, mas fazem espécie de alusões a eles, dando ao mesmo tempo a entender que é impossível encontrar um nome preciso para eles". De fato, ao lermos Dostoiévski sempre nos deparamos com as falas dos personagens que não conseguem se expressar, gaguejam, repetem as palavras. Além disso, temos a sensação de que "algo", talvez o mais importante, deixou de ser dito. Em relação a isso, Lotman cita um trecho de $O$ idiota:

... em qualquer pensamento genial ou no novo pensamento humano, ou simplesmente até em qualquer pensamento humano sério, que medra da cabeça de alguém, sempre resta algo que de maneira nenhuma se pode transmitir a outras pessoas, embora você tenha garatujado volumes inteiros e passado trinta e cinco anos interpretando o seu pensamento; sempre resta algo que de maneira alguma desejará sair do seu crânio e permanecerá com você para todo o sempre; e assim você acaba morrendo sem ter transmitido a ninguém talvez o mais importante da sua ideia (DOSTOIÉVSKI, 2002, p. 440).

Aqui Dostoiévski se aproxima das concepções românticas da palavra resumidas por um dos maiores representantes do romantismo em solo russo, Vassíli Jukóvski, que indagava se o "inefável pode ser expresso". Certamente foi sob a influência de Bakhtin que Lotman conclui ser a palavra de Dostoiévski muito complexa. Por um lado, em sua obra sempre se destaca a incoerência entre a palavra e o seu significado: muitas vezes os personagens não são capazes de expressar aquilo que sentem. Por outro lado, ao contrário da palavra em Tolstói, que se afasta da verdade, a palavra em Dostoiévski se aproxima dela, a alude (Op. cit., p. 246).

A simbologia em Dostoiévski está presente também no nível dos personagens, pois muitos são profundamente simbólicos e representam inclusive vários símbolos 
culturais. Talvez o exemplo mais conhecido seja o príncipe Mýchkin, relacionado ao Cristo pelo próprio Dostoiévski, porém Lotman lembra também de outra protagonista do romance, Nastássia Filíppovna, que condensa diversos símbolos da cultura universal: ela é, ao mesmo tempo, a Dama das Camélias, a Susana e a pecadora da Bíblia. De acordo com Lotman, o principal atributo de um símbolo cultural é "acumular e organizar ao seu redor as novas experiências, transformando-se em uma espécie de condensador da memória" (Op. cit., p. 248). Nos escritos de Dostoiévski esses símbolos, por um lado, remetem a arquétipos culturais, mas, por outro, recebem uma abordagem inusitada.

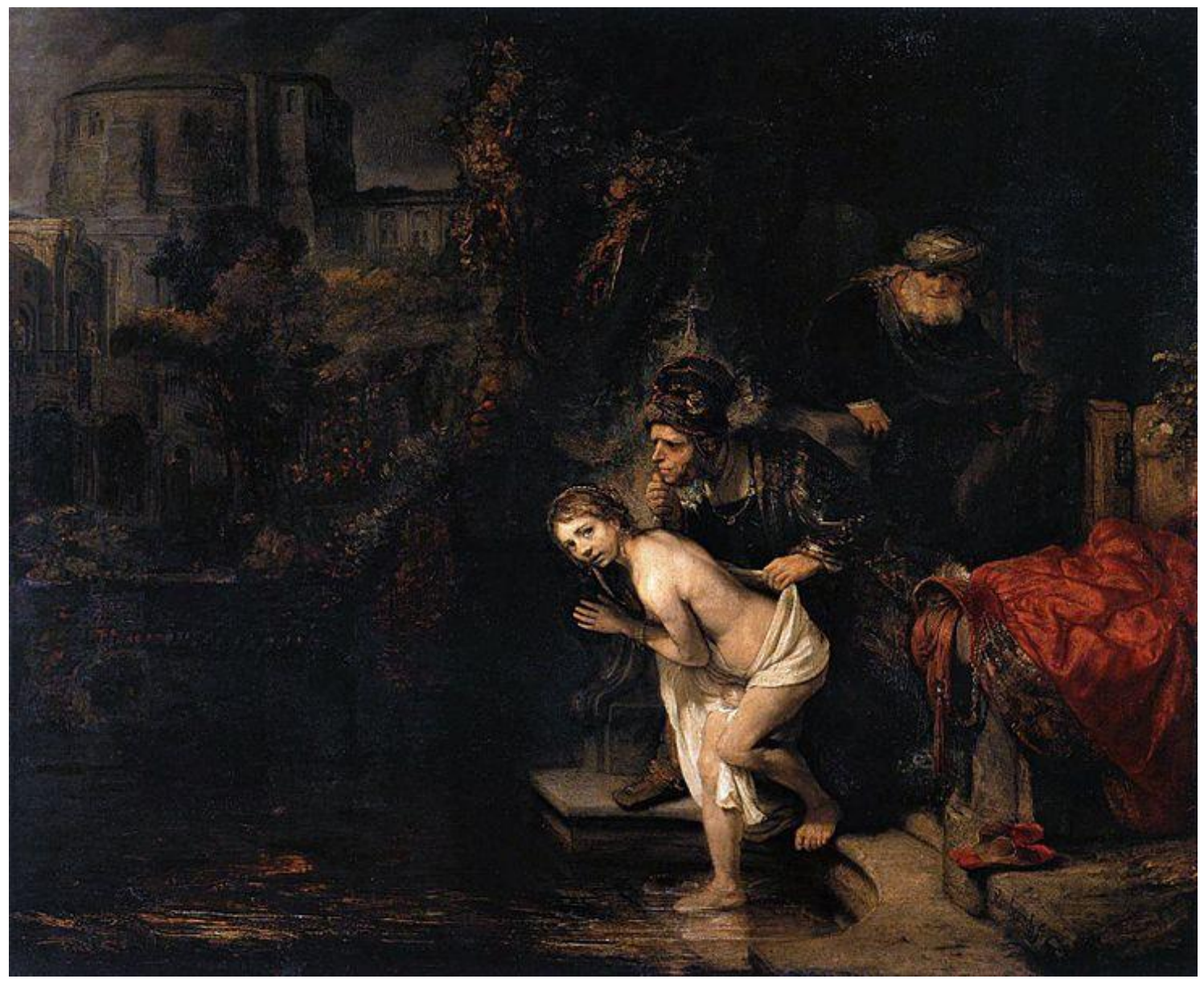

Quadro de Rembrandt Susana e os velhos (1647), que segundo Lotman serviu de inspiração para a criação da personagem de Nastássia Filíppovna em $O$ idiota.

Outro motivo transcultural que se manifestou em Dostoiévski é o do personagem duplo. Por exemplo, encontramos esse motivo em $O$ homem de areia, de Hoffmann, em $O$ nariz e $O$ capote, de Gógol, e em William Wilson, de Edgar Allan Poe. Em Dostoiévski, além da novela $O$ duplo, ele aparece em Os irmãos Karamázov: os 
próprios irmãos duplicam um a outro e, ao mesmo tempo, todos estão correlacionados à figura do pai, Fiódor Karamázov. Ele aparece como uma espécie de ponto de referência: cada um dos irmãos representa o grau de degradação ou elevação moral em relação a ele (LOTMAN, 2001, 283).

\section{Considerações finais}

Apesar da ausência, na extensa obra lotmanina, de trabalhos dedicados especificamente a Dostoiévski e sua criação, ele é citado constantemente e muitas vezes ao lado de Tolstói. Apesar de representarem os modelos semióticos opostos, o binário e o ternário, são partes indissolúveis da literatura russa. Segundo Lotman, e o par Dostoiévski-Tolstói, que se encontra em relações de contradição e complementação mútua, marcou o período-chave para a cultura russa. Como resultado das reformas de Pedro, o Grande, no século XVIII, aconteceu a dessacralização da cultura russa. O lugar antes ocupado pela religião aos poucos foi tomado pela literatura secular:

...a cultura russa, começando por século XVIII até Gógol, Dostoiévski e Tolstói, assumiu uma função que antes, na cultura medieval, possuía caráter sacral. A arte (e principalmente a literatura) assumiu a função religiosa e ética que não lhe pertencia. Da mesma forma, isso se estendeu para a filosofia (o que condicionou a especificidade da escola filosófica russa) e para a publicística e tornou-se uma função universal da linguagem da cultura como um todo. (LOTMAN, 2001, p. 661).

No ensaio "A literatura russa da época pós-petrina e a tradição cristã" (1994), Lotman afirma que, nesse processo, o poeta e o escritor começam a ser vistos como profetas:

Dentro dessa cultura, o escritor, em ideal, não era um criador de texto, mas o seu transmissor, portador da verdade superior. [...] À literatura foi atribuída função profética que decorria naturalmente da concepção religiosa medieval da natureza da Palavra (LOTMAN, 1994, p. 365).

A criação da literatura secular, cujos objetivos divergiam da literatura religiosa, deveria eliminar o elemento místico presente na palavra escrita, mas não foi o que aconteceu: "Desse modo, o poeta aparece como portador da verdade superior e a palavra poética adquire o valor da palavra vinda de cima, dotada de uma autoridade especial, tornando-se a Palavra" (Op. cit., p. 367). Essa é a origem das relações tortuosas entre a Palavra e a Verdade, presentes na obra de Dostoiévski e Tolstói. 
Não apenas a obra do poeta, como também a sua vida pessoal, precisava obedecer às regras rígidas de moralidade. Encontramos aqui uma diferença significativa entre a cultura russa e a europeia: se na Europa Ocidental a vida pessoal do escritor e a sua obra existiam em duas dimensões distintas, na Rússia "o direito de falar em nome da Verdade" tinha que ser conquistado com uma façanha pessoal, com um auto-sacrifício" (Op. cit., p. 368). Em decorrência disso, a própria biografia do escritor também se torna uma obra de arte:

Todo esse trabalho cultural complexo acabou por criar duas grandes biografias: a de Tolstói e a de Dostoiévski; biografias sem as quais é impossível compreender nem a obra desses escritores nem a cultura do século XIX em geral (LOTMAN, 1997, p.816).

Além disso, justamente com Dostoiévski e Tolstói inicia-se a "exportação" dos textos russos para fora do país, ou, segundo a terminologia semiótica, a cultura russa deixa de ser "receptora" de textos de outras culturas e passa a ser "emissora" dos seus próprios textos (LOTMAN, 2001, p. 275). Por todas essas razões, o par DostoiévskiTolstói perpassa toda a obra lotmaniana, tanto no que diz respeito à semiótica, quanto à crítica literária.

Por fim, há uma questão curiosa que Lotman levanta em vários de seus textos: se um grande poeta ou escritor como, por exemplo, Púchkin ou Dostoiévski não tivesse existido, a história da cultura e literatura russa teria sido a mesma? Não, ela seguiria outros caminhos, totalmente imprevisíveis (LOTMAN, 2001, p. 59). A explosão cultural universal produzida pela literatura russa deve-se essencialmente à individualidade dos seus criadores.

Apresentamos, de forma breve, algumas abordagens semiótico-literárias da obra de Dostoiévski, inseridas no universo da literatura russa, que, por sua vez, representa uma estrutura semiótica complexa. Um dos seus atributos basilares é a dinamicidade, o movimento constante. Não se trata apenas da sequência cronológica, mas também das "relações dialógicas" com as épocas posteriores. "Assim como é impossível atravessar duas vezes o mesmo rio, é impossível aprender, de uma vez por todas, a história da literatura, pois o rio muda" (LOTMAN, 1997, p. 604). Sem dúvida, o mesmo pode ser dito em relação à herança de Dostoiévski e à sua recepção, que foi diferente na União Soviética e na Rússia atual. Tudo se torna ainda mais complexo se falarmos da sua recepção no exterior e, inclusive, no Brasil, pois nesse caso entram em cena as questões de tradução interlingual, mas também intercultural e intersemiótica. Por exemplo, como traduzir a palavra ístina (a verdade absoluta) tão cara para Dostoiévski e fundamental na 
concepção lotmaniana sobre a literatura russa? A nosso ver, um dos exemplos mais interessantes dessa recepção brasileira e, ao mesmo tempo, da tradução intercultural são as ilustrações brasileiras das obras de Dostoiévski, entre as quais se destacam as gravuras de Oswaldo Goeldi para a Editora José Olympio. Tomamos como exemplo a seguinte ilustração de $O$ idiota:

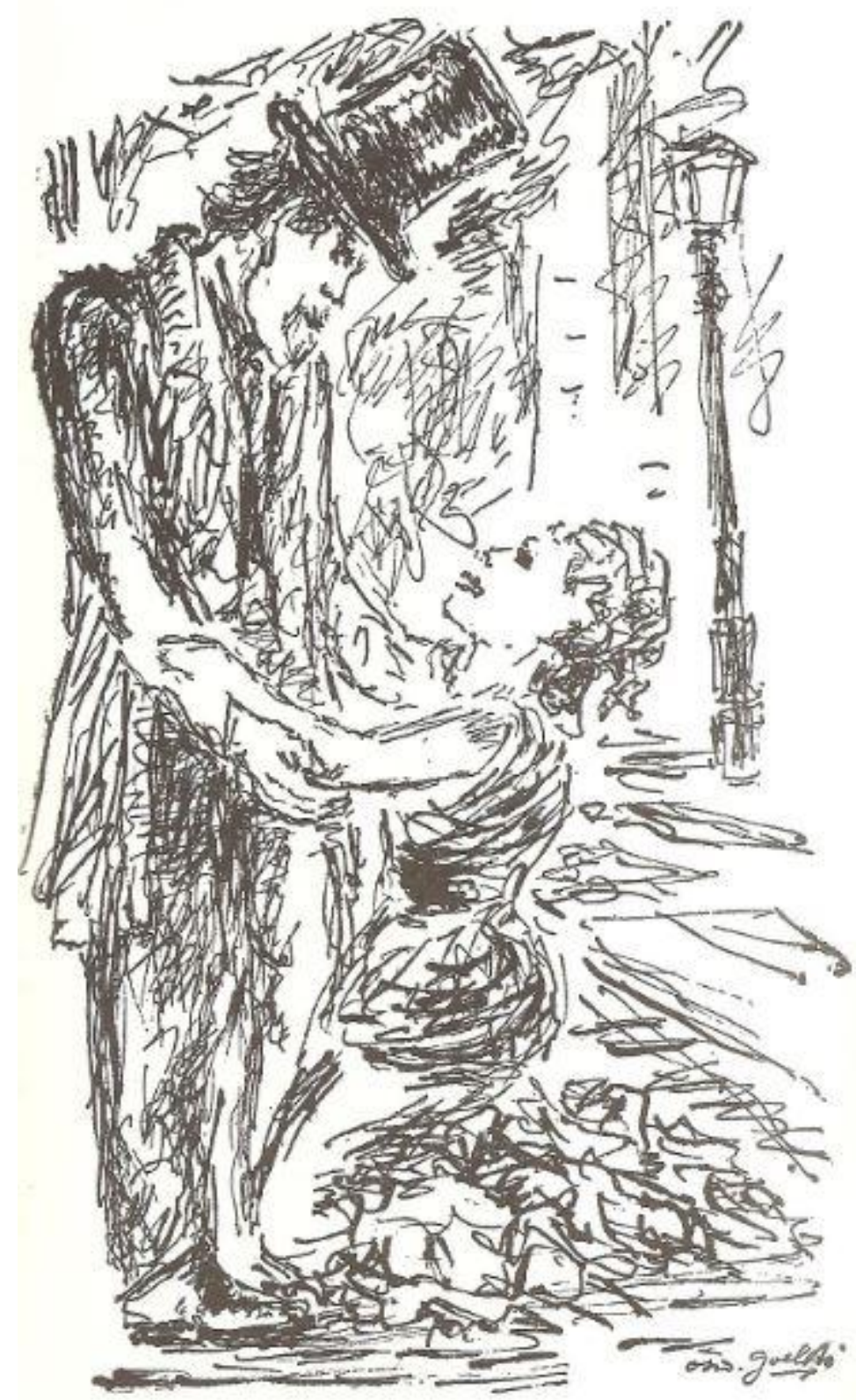

O príncipe Mýchkin e Nastássia Filíppovna. (Fonte: DOSTOIÉVSKI, 2002, p. 511).

O que chama a atenção nessa gravura é a imprecisão dos contornos, compostos por linhas emaranhadas, às vezes em direções opostas. Por um lado, deve se tratar do estilo artístico de Goeldi, mas, por outro, essa imprecisão por certo é proposital: ela abre possibilidade para inúmeras interpretações. Pela mesma razão, apesar de alguns detalhes 
"cronotópicos" (como o poste de luz tipicamente "petersbuguês" ao fundo e o chapéu de Mýchkin), a gravura encontra-se fora dos limites de tempo e espaço: ela poderia ilustrar alguma obra de Machado de Assis ou até mesmo de um autor moderno.

\section{Bibliografia}

AMÉRICO, Edelcio. Texto de São Petersburgo na literatura russa. Dissertação de mestrado. USP, 2006.

DOSTOIÉVSKI, Fiódor. Crime e castigo. [Tradução de Paulo Bezerra]. São Paulo: Ed. 34, 2001.

O idiota. [Tradução de Paulo Bezerra]. São Paulo: Ed. 34, 2002.

LOTMAN, Iúri. O rússkói literatúre. (Sobre a literatura russa). São Petersburgo: Iskússtvo-SPB, 1997. Semiosfera. São Petersburgo: Iskússtvo-SPB, 2001.

Púchkin. (Пушкин). São Petersturgo: Isskustvo-SPB, 2003.

Rússkaia literatura poslepetróvskoi epokhi i khristiánskaia tradítsia. (A literatura russa da época pós-petrina e a tradição cristã). In: Iu. M. Lotman i tártusskomoskóvskaia semiotítcheskaia chkola. (Iu. M. Lotman e a escola semiótica de TártuMoscou). Moscou: Gnózis, 1994, p. 364-379.

NEKLIÚDOV, Serguei. A folclorística russa e as pesquisas semióticas estruturais. In: Mitopoéticas: da Rússia às Américas. [Org. Aurora Fornoni Bernardini, Jerusa Pires Ferreira; co-organização Programa de Pós-graduação em Literatura e Cultura russa USP e Núcleo de Poéticas da Oralidade - PUC-SP.] São Paulo: Humanitas, 2006, p. 17. 27. 